\title{
Anti-inflammatory role of curcumin in retinal disorders (Review)
}

\author{
FEDERICA FRANZONE $^{1 *}$, MARCELLA NEBBIOSO $^{1 *}$, TIZIANO PERGOLIZZI $^{1}$, \\ GIUSEPPE ATTANASIO ${ }^{1}$, ANGELA MUSACCHIO ${ }^{1}$, ANTONIO GRECO ${ }^{1}$, PAOLO GIUSEPPE LIMOLI ${ }^{2}$, \\ MARCO ARTICO $^{1}$, DEMETRIOS A. SPANDIDOS ${ }^{3}$, SAMANTA TAURONE $^{4 * *}$ and ENZO AGOSTINELLI ${ }^{1,5^{* *}}$ \\ ${ }^{1}$ Department of Sensory Organs, Faculty of Medicine and Dentistry, Sapienza University of Rome, I-00161 Rome; \\ ${ }^{2}$ Low Vision Research Centre of Milan, I-20145 Milan, Italy; ${ }^{3}$ Laboratory of Clinical Virology, Medical School, \\ University of Crete, Heraklion 71003, Greece; ${ }^{4}$ IRCCS-Fondazione Bietti, I-00198 Rome; \\ ${ }^{5}$ International Polyamines Foundation ETS-ONLUS, I-00159 Rome, Italy
}

Received January 23, 2021; Accepted April 20, 2021

DOI: $10.3892 / \mathrm{etm} .2021 .10222$

\begin{abstract}
Curcumin [1,7-bis-(4-hydroxy-3-methoxyphenyl) -hepta-1,6-diene-3,5-dione], the main component of turmeric (Curcuma longa, a flowering plant of the ginger family, Zingiberaceae), is known to possess different pharmacological activities, particularly anti-inflammatory and antioxidant properties. Since an underlying inflammatory process exists in several ocular conditions, such as anterior uveitis, glaucoma, age-related macular degeneration (AMD) and diabetic retinopathy (DR), the aim of the present review was to summarize the pleiotropic effects exerted by this molecule, focusing in particular on its beneficial role in retinal diseases. The anti-inflammatory activity of curcumin has also been described in numerous systemic inflammatory pathologies and tumors. Specifically, the biological, pharmaceutical and nutra-
\end{abstract}

Correspondence to: Professor Enzo Agostinelli, Department of Sensory Organs, Faculty of Medicine and Dentistry, Sapienza University of Rome, Policlinico Umberto I, Viale del Policlinico 155, I-00161 Rome, Italy

E-mail: enzo.agostinelli@uniroma1.it

${ }^{* * * *}$ Contributed equally

Abbreviations: COX-2, cyclooxygenase 2; TNF- $\alpha$, tumor necrosis factor- $\alpha$; DMC, demethoxycurcumin; BDMC, bis-demethoxycurcumin; ROS, reactive oxygen species; NF- $\mathrm{B}$, nuclear factor- $\mathrm{B}$; IL, interleukin; JAK/STAT, Janus kinase/signal transducer and activator of transcription; CurDD, curcumin diethyldisuccinate; DR, diabetic retinopathy; AMD, age-related macular degeneration; RPE, retinal pigment epithelial cells; PVR, proliferative vitreoretinopathy; RIRI, retinal ischemia-reperfusion injury; RP, retinitis pigmentosa; anti-VEGF, anti-vascular endothelial growth factor; ERK, extracellular signal-regulated kinase; JNK, c-Jun N-terminal kinase; MNU, methyl-N-nitrosourea; $\mathrm{RB}$, retinoblastoma

Key words: curcumin, ROS, protein kinases, epidermal growth factor, DR, polymeric micelles ceutical properties of curcumin are associated with its ability to downregulate the expression of the following genes: IкB $\alpha$, cyclooxygenase 2, prostaglandin E2, interleukin (IL)-1, IL-6, IL-8 and tumor necrosis factor- $\alpha$. According to this finding, curcumin may be useful in the treatment of some retinal disorders. In DR, proliferative vitreoretinopathy and AMD, beneficial effects have been observed following treatment with curcumin, including slowing down of the inflammatory process. Despite the aforementioned evidence, the main disadvantage of this substance is that it possesses a low solubility, as well as poor oral bioavailability due to its reduced absorption, rapid metabolism and rapid elimination. Therefore, several curcumin analogues have been synthesized and tested over the years, in order to improve the possible obtainable therapeutic effects. The purpose of the present review was to identify new aspects that could guide future research on this important traditional medicine, which is a well-tolerated natural product, and is widely considered safe and economical.

\section{Contents}

1. Introduction

2. Methodology

3. Therapeutic effects of curcumin in retinal diseases

4. AMD

5. DR

6. PVR

7. RIRI

8. RP

9. Retinal and choroidal tumors

10. COVID and curcumin

11. Conclusions

\section{Introduction}

Curcumin: Chemical structure. Curcumin (1,7-bis[4-hydroxy3-methoxyphenyl]-1,6-heptadiene-3,5-dione) is a hydrophobic and insoluble yellowish-orange colored polyphenol and the major bioactive component of turmeric (Curcuma longa). 
It is also known as Diferuloylmethane or E100, in relation to the European coding of food additives (1). Another term commonly used to refer to this substance is 'Curcumin I' (2). Considering its pleiotropic action, curcumin belongs to the group of phytocompounds, which can be defined as biologically active molecules produced by plants with positive effects on health (3). In 1815, more than 140 years ago, Vogel isolated it from the Curcuma longa rhizomes, a traditional perennial plant belonging to the Zingiberaceae family. Later, in 1913, Lampe synthesized this molecule (4).

Owing to its anti-inflammatory, antioxidant, antimicrobial, anti-angiogenesis, antimutagenic and neuroprotection properties (5-9), curcumin is considered to be a nutraceutical substance for the treatment of several chronic diseases $t$ such as diabetes, atherosclerosis, rheumatism, infectious and oncological diseases (brain, lung, breast and colon cancer) (10-12).

From a commercial point of view, the most interesting component of the plant is represented by Curcuma Longa's roots: Once the rhizomes are boiled and dried in the sun, they are crushed in order to produce a yellow-orange powder, whose biologically active compound is curcumin which accounts for $2-5 \%$ of turmeric extract $(5,13)$ (Fig. 1).

Apart from this molecule, demethoxycurcumin (DMC) and bis-demethoxycurcumin (BDMC) represent the major turmeric curcuminoids: More specifically, DMC and BDMC present biological properties quite similar to those of curcumin, being able to suppress the activity of enzymes such as COX-2, responsible for nuclear factor $-\kappa \mathrm{B}(\mathrm{NF}-\kappa \mathrm{B})$ activation. Conversely, the turmeric volatile fraction includes terpene compounds, such as zingiberene, curcumol and $\beta$-turmerone $(14,15)$.

Curcumin: Properties. The most promising feature of curcumin is its anti-inflammatory and antioxidant activity: Normally, inflammation represents a physiological and protective response of the body to a series of events which can be result in organic damage. Closely related to inflammation processes is oxidative stress, which is commonly defined as an imbalance between reactive oxygen species (ROS) and antioxidant defenses (16).

A situation of persistent oxidative stress can trigger several inflammatory molecular signaling pathways: For instance, ROS may lead to an improvement in the NF- $\mathrm{NB}$ and the tumor necrosis factor $\alpha$ (TNF- $\alpha)(17,18)$. Nowadays, it is assumed that curcumin's anti-inflammatory and antioxidant properties are mainly related to its hydroxyl and methoxy groups.

Curcumin leads to deregulation of TNF- $\alpha$ and proinflammatory interleukins (IL-1, IL-2, IL-6, IL-8 and IL-12) owing to its ability to down regulate the Janus kinase/signal transducer and activator of transcription (JAK/STAT) pathway.

Despite all these positive aspects, curcumin presents some important limitations: First of all, it has extremely poor bio-availability, supported by evidence that the biologically active fraction registered in the blood is minimal; secondly, the need for high levels of the substance ( $>3.6 \mathrm{~g} /$ day in humans) in order to achieve any therapeutic effects (19).

Curcumin: Limitations of use. Therefore, in order to overcome these strict limitations, several approaches such as curcumin analogues, enhancers and delivery systems have been taken into consideration.
Regarding curcumin analogues, some of the more promising substances appear to be the pro-drug diphosphorylated curcumin, which is characterized by a higher molecular stability in the aqueous media (20), the curcumin pro-drug curcumin diethyl disuccinate (CurDD) (12) and WZ35, with stronger anti-tumoral properties $(21,22)$.

'Bioavailability enhancers' have been considered even more encouraging: This definition refers to compounds which improve substance availability. In the case of curcumin, there has been a great interest in piperine owing to its ability to decrease curcumin hepatic and intestinal glucuronidation (23) with consequent augmentation of curcumin bioavailability. This pharmacological effect was demonstrated by comparing serum curcumin concentration when given alone versus administration together with piperine. In this last case, curcumin blood levels presented a significant increase (24).

Another field of great interest is represented by curcumin carriers: For instance, nanoparticles, able to ameliorate curcumin bioavailability, solubility and stability in aqueous media (25), liposomes (26), which are spherical bilayer vesicles with a size approximately between 25-1,000 nm, and polymeric micelles (27-29).

One of the most encouraging delivery systems for curcumin is an amphiphilic polymer polyvinyl caprolactam-polyvinyl acetate-polyethylene glycol graft copolymer (Soluplus ${ }^{\circledR}$ ), which presents both a hydrophilic and a lipophilic component $(25,30)$.

Unfortunately, it must be clarified that most of these strategies have not yet been tested in the eye: Nevertheless, use of a biodegradable curcumin-loaded scleral plug for treatment of posterior ocular diseases experimented in rabbit eyes represents an exception, with high levels of curcumin obtained both in vitro and in vivo (31). In addition, a further vehicle is Meriva $^{\circledR}$, a curcumin-phospholipid lecithin formulation, able to improve visual acuity and reduce macular edema in DR patients when administered twice a day as tablets (Norflo ${ }^{\circledR}$, Eye Pharma, Genoa, Italy) $(32,33)$.

In ophthalmology, an initial approach with curcumin was attempted as part of the treatment of complicated chronic anterior uveitis: An improvement in symptoms was observed after a 12-week treatment dose of $375 \mathrm{mg}$ three times a day (34).

The chemical and biological properties of curcumin make this substance capable of exerting anti-inflammatory, antioxidant, antimicrobial and anti-tumorigenic activity. Thanks to these properties, curcumin has been studied in vitro and in vivo, also in the context of many inflammatory, autoimmune, congenital and degenerative eye diseases of both the anterior and posterior segments, and has been used as an adjuvant therapy (35-37). The main problem with the oral use of curcumin is its poor bioavailability caused by low gastrointestinal absorption and rapid hepatic and intestinal metabolism. Considering the strong evidence demonstrating the 'weakness' of isolated curcumin as a valid therapy, the evaluation of holistic approaches that take into account the chemistry and complexity of the pharmacodynamics/pharmacokinetics of turmeric and its broad nutritional basis compared to traditional drugs seems to be the direction for future research in this field. The purpose of our work is to identify new aspects that could guide future research on this important traditional medicine 


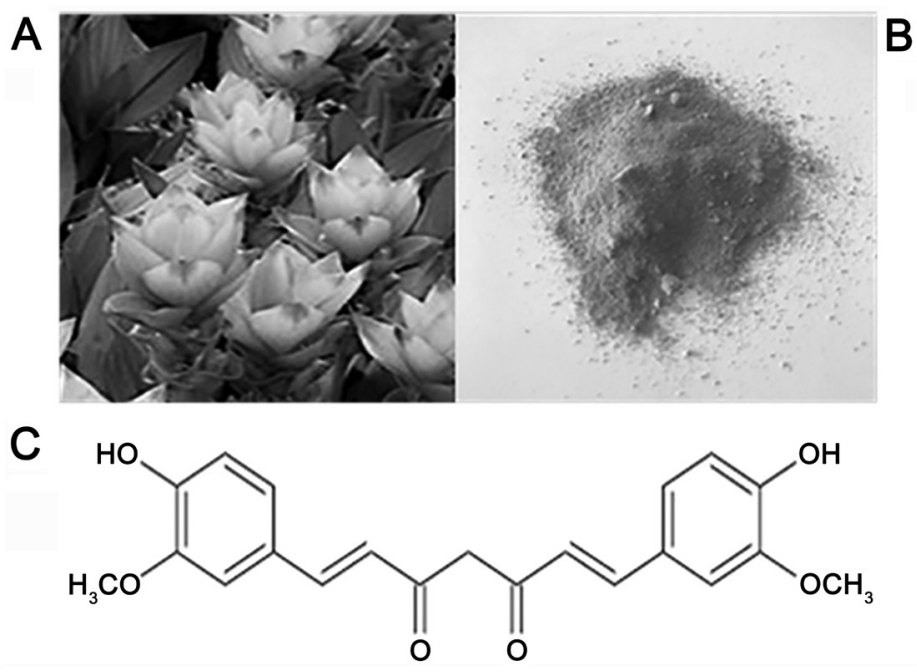

Figure 1. Curcuma longa. (A) Turmeric flowers, (B) root and (C) its chemical structure.

especially in view of the fact that it is a well-tolerated, natural product, considered safe and economical.

\section{Methodology}

For this review, we searched the PubMed database without language limitations for articles regarding curcumin. Using the 'Advanced Search Builder' tool, the terms 'curcumin', 'inflammation' and 'eye diseases' were used with the terms 'anti-inflammatory', 'retinopathy', 'antioxidants', 'extracellular matrix remodeling', 'oxidative stress 'and' angiogenesis 'included in the title or abstract of the articles. The documents published up to December 2020 were included. All the publications have been carefully studied, to select those most relevant to our topic. The references reported in the selected papers were also examined. Finally, a web search engine was also used (Google). We have not used any exclusion criteria for this research

\section{Therapeutic effects of curcumin in retinal diseases}

Nowadays, it is well-known that in a wide group of retinal diseases an inflammatory pathogenesis can be identified: The retina, considered as part of the central nervous system, is characterized by the presence of different cell types, including two types of photoreceptors: Cones, principally located in the macula lutea, and rods, mostly placed in the retinal periphery. These cells, along with retinal ganglion cells and retinal pigment epithelial (RPE) cells, are particularly sensitive to oxidative stress damage. Recent studies have shown that curcumin protects RPE from oxidative stress and damage induced by the inflammatory process by reducing TNF- $\alpha$ levels, recently Bucolo et al (36) has shown that curcumin provides protection against damage induced by oxidative stress in the RPE through activation of Nrf2/HO-1 (nuclear factor erythroid 2-related factor $2 /$ heme oxygenase 1 ) signaling involving modulation of the extracellular signal-regulated kinase (ERK) pathway suggesting that curcumin may have therapeutic value in the treatment of retinal diseases such as diabetic retinopathy (DR) and age-related macular degeneration (AMD) $(36,37)$. More in detail, this nervous tissue is largely subjected to oxidative stress owing to its intrinsic features, such as continuous light exposure, which leads to photooxidation mechanism enhancement. The consequences of this are an improvement of ROS levels, high vascularization and, finally, a high concentration of mitochondria. Oxidative stress is the triggering mechanism in a series of harmful processes: Cell apoptosis, angiogenesis and inflammation leading to a wide range of retinal pathologies. As mentioned above, thanks to its pharmacological properties, curcumin is able to prevent the formation of ROS: Hence it can be properly used in the prevention and treatment of distinct retinal disorders as AMD, DR, proliferative vitreoretinopathy (PVR), retinal ischemia-reperfusion injury (RIRI), retinitis pigmentosa (RP) and retinal and choroid tumors $(1,3,35)$.

\section{AMD}

AMD is the most common cause of irreversible blindness affecting elderly subjects in industrialized countries. AMD exists in two forms: A non-neovascular one (also defined as 'dry' or 'non-exudative') and a neovascular one, characterized by choroidal neovascularization ( also known as 'wet' or 'exudative') (Fig. 2). From a clinical point of view, loss of central vision is one of the most characteristic symptoms referred by patients and is due to progressive macular degeneration. Currently, no treatment is reported to exist for the dry form, while the neovascular one is commonly approached with continued intraocular injections of anti-vascular endothelial growth factor (anti-VEGF) (38). To date, AMD pathogenesis remains unclear: Undoubtedly, inflammation and oxidative stress, along with other risk factors such as aging, smoking, sun exposure and a poor diet, play a major role in AMD (39). As is well-known, the macula is constantly exposed to both oxygen and light and, consequently, a great amount of ROS is produced in this region. ROS lead to the activation of a series of distinct pathways such as the mitogen activated protein kinases, the ERK, the p38 mitogen-activated protein kinase, and the c-Jun N-terminal kinase (JNK). Specifically, the cells that are most damaged are the RPE cells, placed between the 


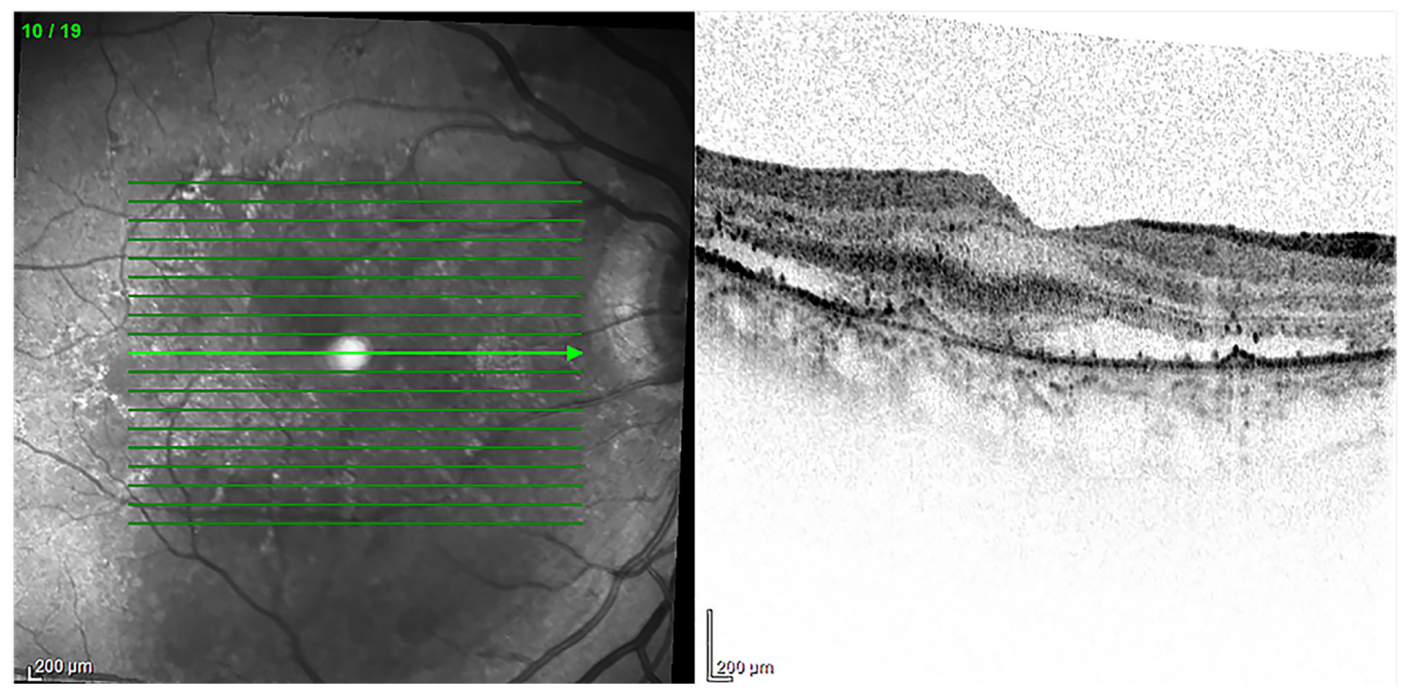

Figure 2. OCT. Wet age-related macular degeneration with choroidal neovascularization. Subretinal fluid and fibrovascular pigment epithelial detachment were also evident on the OCT. Diagnostic images provided by Professor M. Nebbioso. OCT, optical coherence tomography.

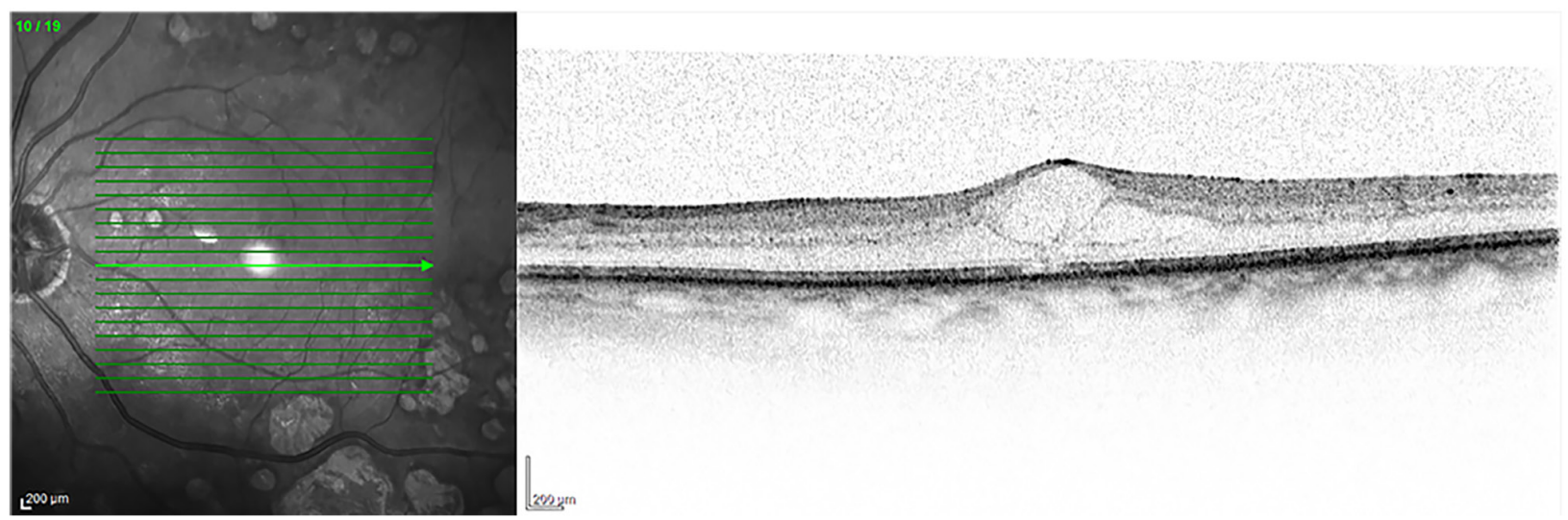

Figure 3. OCT. Diabetic retinopathy with cystoid macular edema. OCT showed a retinal section with cystic spaces at the macula. Diagnostic images provided by Professor M. Nebbioso. OCT, optical coherence tomography.

choroid and the photoreceptors, leading to AMD development. RPE cells are deeply involved in supporting the retina, both being implicated in the photoreceptor outer segments digestion and in blood-retinal barrier maintenance. Thus, Muangnoi et al (40) investigated the protective role of the CurDD against curcumin in relation to oxidative stress induced in human ARPE-19 cells (Retinal Pigment Epithelial immortalized cell line derived from Amy Aotaki-Keen eyes), the most widely used experimental model cells. They showed that CurDD, like curcumin, is able to downstream a fundamental apoptotic signaling pathway, known as p44/42 (ERK), with a consecutive reduction of their effector molecules Bax and Bcl2 in ARPE-19 cells. Moreover, CurDD revealed a greater protective effect than curcumin against oxidative stress, thus representing a valid alternative option for AMD prevention and treatment $(36,37,40)$.

\section{DR}

DR is considered to be the main cause of irreversible visual loss all over the world in the working-age population (41).
Clinically, it can be defined as a metabolic and microvascular disease (42), characterized by a process of chronic inflammation. Ischemia, microaneurysms, hemorrhages, retinal edema, neuronal degeneration and neovascularization (43) represent the most indicative manifestations of DR (Fig. 3).

Depending on neovascularization, two distinct DR stages can be recognized: Blood flow alterations, pericyte loss and thickening of the basement membrane define the non-proliferative diabetic retinopathy, while a sight-threatening neovascularization is the main feature of the proliferative diabetic retinopathy (44).

In both cases inflammation and oxidative stress are the underlying cause of the DR onset and progression determining damage of photoreceptors and blood vessels with release of cellular mediators able to stimulate angiogenesis (45). Another factor of extreme importance in the DR pathogenesis is the oxidative stress induced by hyperglycemia: Specifically, ROS contribute to the loss of pericytes leading to microaneurysms and, as a consequence, to the vascular syndrome of DR $(46,47)$.

Moreover, free radicals favor an increase of proinflammatory mediators such as VEGF and TNF- $\alpha(48,49)$. 
Several studies have been conducted to evaluate the beneficial effects of curcumin in the case of DR: In 2011 the role of oral curcumin at doses of $1 \mathrm{~g} / \mathrm{kg}$ body weight of streptozotocin-induced diabetic retinopathy in Wistar albino rats was assessed in terms of prevention and treatment. Particularly, curcumin revealed a significant hypoglycemic activity and the ability to positively modulate the antioxidant system, with an increase of SOD and catalase enzymes. Moreover, a decrease of TNF- $\alpha$ and VEGF levels was observed (50).

Interestingly, curcumin is able to normalize the diabetic microvasculature: A decrease in its tortuosity, narrowing and micro-aneurysms was observed. The beneficial effect of curcumin treatment on the microvasculature is also demonstrated by the regeneration and repair mechanisms observed in choroidal microvasculature after curcumin treatment (51).

\section{PVR}

PVR is defined as an eye disorder generally occurring after retinal detachment or re-attachment and often leading to blindness. It can be defined as a form of wound healing process induced by the epidermal growth factor and mainly characterized by RPE cell proliferation and migration. Ren et al (52) described a significant reduction of RPE cell proliferation and of vitreous opacity in the group of patients who received curcumin in comparison with the control group.

\section{RIRI}

In the case of RIRI, a pathological process due to a loss of intraocular perfusion pressure, as a consequence of ocular hypertension, the protective role of curcumin on retinal neurons was described by Wang et al (53). They found that curcumin is able to inhibit both NF- $\kappa$ B and STAT3 (signal transducer and activator of transcription) and the consequent over-expression of monocyte chemoattractant protein 1 in Wistar rats (53).

The protective role of curcumin was also observed in retinal neurons and capillaries in stroke spontaneously hypertensive rats (SHR), where curcumin is able to down-regulate the JNK expression (54).

\section{RP}

Curcumin has also been attempted as an optional treatment in $\mathrm{RP}$, a group of disorders characterized by a progressive degeneration of photoreceptors which inexorably leads to blindness. It can be defined as a heterogeneous disease including both syndromic and non-syndromic forms and involving a great number of genes, with different patterns of transmission and distinct phenotypic presentation (55).

In this regard, a promising discovery was made by Vasireddy et al (56): The $\mathrm{P} 23 \mathrm{H}$ mutation in the rhodopsin gene determines a rhodopsin misfolding with the formation of insoluble aggregates. The consequence of this is a form of autosomal dominant RP. They observed that the treatment of COS-7 cells expressing mutant rhodopsin with curcumin leads to aggregate dissociation: In light of this, they administered curcumin to $\mathrm{P} 23 \mathrm{H}$-rhodopsin transgenic rats and, in this way, were able to demonstrate the anti-protein, aggregating activity of curcumin (56).
Curcumin is also able to prevent photoreceptor apoptosis triggered by the ROS generator methyl-N-nitrosourea (MNU) tested in a Sprague-Dawley rat model. As highlighted by Emoto et al (57), the rats firstly received MNU and were then injected with doses of 100 or $200 \mathrm{mg} / \mathrm{kg}$ of curcumin. A reduction of central retinal damage was observed (57).

\section{Retinal and choroidal tumors}

Considering that curcumin's pharmacological activities have been studied in the treatment of various oncological diseases, it is not surprising that its use has also been evaluated in a form of retinal tumor, the retinoblastoma (RB). The pathogenesis of this retinal cancer is usually due to the biallelic loss of RB1, a tumor suppressor gene, in association with both genetic and epigenetic modifications. In particular, one study highlighted the ability of curcumin to determine RB cell proliferation and migration as well as induce their apoptosis. The pathway along which curcumin acts is the JAK/STAT with its consequent inactivation (58). Curcumin anti-cancer activity has even been reported in tumors not directly originating in the retina, such as intraocular lymphoma, able to cause ocular metastasis (59).

\section{COVID and curcumin}

The mechanism underlying the effect of curcuminoids is inhibition and blocking of free radicals before they develop and spread. Besides the anti-inflammatory and analgesic activity, antibacterial and antiviral, hepatoprotective, cholesterol-lowering and antithrombotic activities have also been demonstrated. In the latter case, the antioxidant activity has proved particularly effective in limiting oxidative damage to the vessel walls. Oxidation of the structures of the vessel membranes is in fact one of the main prerequisites for the formation of a thrombus. The correlation between inflammatory diseases, such as pneumonia and thrombosis in general (especially venous), has been known for decades. In fact patients with any bacterial or viral form of pneumonia, not necessarily from SARS-CoV-2, are routinely subjected to thromboembolic prophylaxis with low molecular weight heparin. In a recent work the authors have addressed the thrombotic complications in the context of SARS-CoV-2 (60).

\section{Conclusions}

Considering what has been said so far, it clearly emerges that curcumin, the main polyphenolic compound of the food flavoring turmeric, has gained significant interest due to its biological anti-tumoral, antioxidant, immune-modulating, anti-inflammatory, antiparasitic and antiviral properties $(61,62)$. For this reason, it has been extensively studied in different fields of medicine, in general, and particularly, in ophthalmology, where inflammatory cytokines are involved in the development of many ocular diseases, such as conjunctivitis, keratitis, uveitis, glaucoma, age-related macular degeneration and diabetic retinopathy (63-68).

Since a wide range of beneficial properties have been identified at different levels, much work still needs to be done in order to overcome some important limitations inherent to this substance, such as its bio-availability. Not least, it is important 
to emphasize that curcumin is included in the food and drug category 'generally regarded as safe' (69).

In the light of this, curcumin can be also considered a promising and alternative option in several retinal diseases: In future perspectives we can expect that from having a niche role it could gradually assume an increasingly important position in the treatment of a wide range of both retinal and ocular diseases.

\section{Acknowledgements}

Not applicable.

\section{Funding}

This paper was financially supported by Ministry of Health (grant no. RC 2765943) and Fondazione Roma.

\section{Availability of data and materials}

Not applicable.

\section{Authors' contributions}

ST, EA, FF and MN designed the study. TP, GA, AM, AG, PGL, MA, DAS and FF consulted the literature and collected bibliographical data. ST and FF wrote the paper. EA and ST reviewed and edited the manuscript. Data authentication is not applicable. All authors have read and approved the final manuscript.

\section{Ethics approval and consent to participate}

Not applicable.

\section{Patient consent for publication}

Written informed consent for publication of images was obtained from individuals whose data are included in this manuscript.

\section{Competing interests}

DAS is the Editor-in-Chief for the journal, but had no personal involvement in the reviewing process, or any influence in terms of adjudicating on the final decision, for this article. The other authors declare that they have no competing interests.

\section{References}

1. López-Malo D, Villarón-Casares CA, Alarcón-Jiménez J, Miranda M, Díaz-Llopis M, Romero FJ and Villar VM: Curcumin as a Therapeutic Option in Retinal Diseases. Antioxidants 9: 48, 2020.

2. Anand P, Kunnumakkara AB, Newman RA and Aggarwal BB: Bioavailability of curcumin: Problems and promises. Mol Pharm 4: 807-818, 2007.

3. Peddada KV, Brown A, Verma V and Nebbioso M: Therapeutic potential of curcumin in major retinal pathologies. Int Ophthalmol 39: 725-734, 2019.

4. Noorafshan A and Ashkani-Esfahani S: A review of therapeutic effects of curcumin. Curr Pharm Des 19: 2032-2046, 2013.

5. Deogade SC and Ghate S: Curcumin: Therapeutic applications in systemic and oral health. Int J Biol Pharm Res 6: 281-290, 2015.
6. Gupta SC, Kismali G and Aggarwal BB: Curcumin, a component of turmeric: From farm to pharmacy. Biofactors 39: 2-13, 2013.

7. Lestari ML and Indrayanto G: Curcumin. Profiles Drug Subst Excip Relat Methodol 39: 113-204, 2014.

8. Mahady GB, Pendland SL, Yun G and Lu ZZ: Turmeric (Curcuma longa) and curcumin inhibit the growth of Helicobacter pylori, a group 1 carcinogen. Anticancer Res 22: 4179-4181, 2002.

9. Reddy DNK, Huang FY, Wang SP and Kumar R: Synergistic antioxidant and antibacterial activity of curcumin-C3 encapsulated chitosan nanoparticles. Curr Pharm Des 26: 5021-5029, 2020.

10. Ammon HP and Wahl MA: Pharmacology of Curcuma longa. Planta Med 57: 1-7, 1991.

11. Allegra A, Innao V, Russo S, Gerace D, Alonci A and Musolino C: Anticancer activity of curcumin and its analogues: preclinical and clinical studies. Cancer Invest 35: 1-22, 2017.

12. Muangnoi C, Ratnatilaka Na Bhuket P, Jithavech P, Supasena W, Paraoan L, Patumraj S and Rojsitthisak P: Curcumin diethyl disuccinate, a prodrug of curcumin, enhances anti-proliferative effect of curcumin against HepG2 cells via apoptosis induction. Sci Rep 9: 11718, 2019.

13. Priyadarsini KI: The chemistry of curcumin: From extraction to therapeutic agent. Molecules 19: 20091-20112, 2014.

14. Guo LY, Cai XF, Lee JJ, Kang SS, Shin EM, Zhou HY, Jung JW and Kim YS: Comparison of suppressive effects of demethoxycurcumin and bisdemethoxycurcumin on expressions of inflammatory mediators in vitro and in vivo. Arch Pharm Res 31: 490-496, 2008

15. Pescosolido N, Giannotti R, Plateroti AM, Pascarella A and Nebbioso M: Curcumin: Therapeutical potential in ophthalmology. Planta Med 80: 249-254, 2014.

16. Radomska-Leśniewska DM, Osiecka-Iwan A, Hyc A, Góźdź A, Dábrowska AM and Skopiński P: Therapeutic potential of curcumin in eye diseases. Cent Eur J Immunol 44: 181-189, 2019.

17. Shishodia S, Sethi G and Aggarwal BB: Curcumin: Getting back to the roots. Ann N Y Acad Sci 1056: 206-217, 2005.

18. Singh S and Aggarwal BB: Activation of transcription factor NF-kappa B is suppressed by curcumin (diferuloylmethane) [corrected]. J Biol Chem 270: 24995-25000, 1995. Erratum in: J Biol Chem 270: 30235, 1995.

19. Strimpakos AS and Sharma RA: Curcumin: Preventive and therapeutic properties in laboratory studies and clinical trials. Antioxid Redox Signal 10: 511-545, 2008.

20. Wang J, Xiong T, Zhou J, He H, Wu D, Du X, Li X and Xu B: Enzymatic formation of curcumin in vitro and in vivo. Nano Res 11: 3453-3461, 2018.

21. Chen T, Zhao L, Chen S, Zheng B, Chen H, Zeng T, Sun H, Zhong S, Wu W, Lin X, et al: The curcumin analogue WZ35 affects glycolysis inhibition of gastric cancer cells through ROS-YAP-JNK pathway. Food Chem Toxicol 137: 111131, 2020.

22. Wang L, Wang C, Tao Z, Zhao L, Zhu Z, Wu W, He Y, Chen H, Zheng B, Huang X, et al: Curcumin derivative WZ35 inhibits tumor cell growth via ROS-YAP-JNK signaling pathway in breast cancer. J Exp Clin Cancer Res 38: 460, 2019.

23. Ohori H, Yamakoshi H, Tomizawa M, Shibuya M, Kakudo Y, Takahashi A, Takahashi S, Kato S, Suzuki T, Ishioka C, et al: Synthesis and biological analysis of new curcumin analogues bearing an enhanced potential for the medicinal treatment of cancer. Mol Cancer Ther 5: 2563-2571, 2006

24. Shoba G, Joy D, Joseph T, Majeed M, Rajendran R and Srinivas PS: Influence of piperine on the pharmacokinetics of curcumin in animals and human volunteers. Planta Med 64: 353-356, 1998.

25. Li M, Xin M, Guo C, Lin G and Wu X: New nanomicelle curcumin formulation for ocular delivery: Improved stability, solubility, and ocular anti-inflammatory treatment. Drug Dev Ind Pharm 43: 1846-1857, 2017.

26. Barenholz Y: Doxil ${ }^{\circledR}$ - the first FDA-approved nano-drug: Lessons learned. J Control Release 160: 117-134, 2012.

27. Zhang W, Ma W, Zhang J, Song X, Sun W and Fan Y: The immunoregulatory activities of astragalus polysaccharide liposome on macrophages and dendritic cells. Int J Biol Macromol 105: 852-861, 2017.

28. Cabral $\mathrm{H}$ and Kataoka K: Progress of drug-loaded polymeric micelles into clinical studies. J Control Release 190: 465-476, 2014.

29. Sai N, Dong X, Huang P, You L, Yang C, Liu Y, Wang W, Wu H, Yu Y, Du Y, et al: A novel gel-forming solution based on PEG-DSPE/Solutol HS 15 mixed micelles and Gellan gum for ophthalmic delivery of curcumin. Molecules 25: 25, 2019. 
30. Chen Y, Lu Y, Lee RJ and Xiang G: Nano encapsulated curcumin: and its potential for biomedical applications. Int J Nanomedicine 15: 3099-3120, 2020.

31. Zhang J, Sun H, Zhou N, Zhang B and Ma J: Preparation and evaluation of biodegradable scleral plug containing curcumin in rabbit eye. Curr Eye Res 42: 1597-1603, 2017.

32. Mazzolani F, Togni S, Giacomelli L, Eggenhoffner R and Franceschi F: Oral administration of a curcumin-phospholipid formulation (Meriva ${ }^{\circledR}$ ) for treatment of chronic diabetic macular edema: A pilot study. Eur Rev Med Pharmacol Sci 22: 3617-3625, 2018.

33. Steigerwalt R, Nebbioso M, Appendino G, Belcaro G Ciammaichella G, Cornelli U, Luzzi R, Togni S, Dugall M, Cesarone MR, et al: Meriva ${ }^{\circledR}$, a lecithinized curcumin delivery system, in diabetic microangiopathy and retinopathy. Panminerva Med 54 (Suppl 4): 11-16, 2012.

34. Lal B, Kapoor AK, Asthana OP, Agrawal PK, Prasad R, Kumar P and Srimal RC: Efficacy of curcumin in the management of chronic anterior uveitis. Phytother Res 13: 318-322, 1999.

35. Wang LL, Sun Y, Huang K and Zheng L: Curcumin, a potential therapeutic candidate for retinal diseases. Mol Nutr Food Res 57: 1557-1568, 2013.

36. Bucolo C, Drago F, Maisto R, Romano GL, D'Agata V, Maugeri G and Giunta S: Curcumin prevents high glucose damage in retinal pigment epithelial cells through ERK1/2-mediated activation of the Nrf2/HO-1 pathway. J Cell Physiol 234: 17295-17304, 2019.

37. Pittalà V,Fidilio A,Lazzara F, Platania CBM, SalernoL, Foresti R, Drago $\mathrm{F}$ and Bucolo $\mathrm{C}$ : Effects of novel nitric oxide-releasing molecules against oxidative stress on retinal pigmented epithelial cells. Oxid Med Cell Longev 2017: 1420892, 2017.

38. Yonekawa Y, Miller JW and Kim IK: Age-related macular degeneration: advances in management and diagnosis. J Clin Med 4: 343-359, 2015.

39. Ulańczyk Z, Grabowicz A, Cecerska-Heryć E, Śleboda-Taront D, Krytkowska E, Mozolewska-Piotrowska K, Safranow K Kawa MP, Dołęgowska B and Machalińska A: Dietary and lifestyle factors modulate the activity of the endogenous antioxidant system in patients with age-related macular degeneration: correlations with disease severity. Antioxidants 9: 9, 2020.

40. Muangnoi C, Sharif U, Ratnatilaka Na Bhuket P, Rojsitthisak P and Paraoan L: Protective effects of curcumin ester prodrug, curcumin diethyl disuccinate against $\mathrm{H}_{2} \mathrm{O}_{2}$-induced oxidative stress in human retinal pigment epithelial cells: potential therapeutic avenues for age-related macular degeneration. Int J Mol Sci 20: 20,2019.

41. Yau JW, Rogers SL, Kawasaki R, Lamoureux EL, Kowalski JW, Bek T, Chen SJ, Dekker JM, Fletcher A, Grauslund J, et al; Meta-Analysis for Eye Disease (META-EYE) Study Group: Global prevalence and major risk factors of diabetic retinopathy. Diabetes Care 35: 556-564, 2012.

42. Antonetti DA, Klein R and Gardner TW: Diabetic retinopathy. N Engl J Med 366: 1227-1239, 2012.

43. Platania CBM, Fidilio A, Lazzara F, Piazza C, Geraci F, Giurdanella G, Leggio GM, Salomone S, Drago F and Bucolo C: Retinal protection and distribution of curcumin in vitro and in vivo. Front Pharmacol 9: 670, 2018.

44. Roy S, Maiello M and Lorenzi M: Increased expression of basement membrane collagen in human diabetic retinopathy. J Clin Invest 93: 438-442, 1994.

45. Barber AJ: Diabetic retinopathy: Recent advances towards understanding neurodegeneration and vision loss. Sci China Life Sci 58: 541-549, 2015.

46. Wan TT, Li XF, Sun YM, Li YB and Su Y: Recent advances in understanding the biochemical and molecular mechanism of diabetic retinopathy. Biomed Pharmacother 74: 145-147, 2015.

47. Wu Y, Tang L and Chen B: Oxidative stress: Implications for the development of diabetic retinopathy and antioxidant therapeutic perspectives. Oxid Med Cell Longev 2014: 752387, 2014.

48. Aiello LP, Pierce EA, Foley ED, Takagi H, Chen H, Riddle L, Ferrara N, King GL and Smith LE: Suppression of retinal neovascularization in vivo by inhibition of vascular endothelial growth factor (VEGF) using soluble VEGF-receptor chimeric proteins. Proc Natl Acad Sci USA 92: 10457-10461, 1995.

49. Limb GA, Soomro H, Janikoun S, Hollifield RD and Shilling J: Evidence for control of tumour necrosis factor-alpha (TNF-alpha) activity by TNF receptors in patients with proliferative diabetic retinopathy. Clin Exp Immunol 115: 409-414, 1999.
50. Gupta SK, Kumar B, Nag TC, Agrawal SS, Agrawal R, Agrawal P, Saxena R and Srivastava S: Curcumin prevents experimental diabetic retinopathy in rats through its hypoglycemic, antioxidant, and anti-inflammatory mechanisms. J Ocul Pharmacol Ther 27: 123-130, 2011.

51. Khimmaktong W, Petpiboolthai H, Sriya P and Anupunpisit V: Effects of curcumin on restoration and improvement of microvasculature characteristic in diabetic rat's choroid of eye. J Med Assoc Thai 97 (Suppl 2): S39-S46, 2014

52. Ren YX, Ma JX, Zhao F, An JB, Geng YX and Liu LY: Effects of Curcumin on Epidermal Growth Factor in Proliferative Vitreoretinopathy. Cell Physiol Biochem 47: 2136-2146, 2018

53. Wang L, Li C, Guo H, Kern TS, Huang $\mathrm{K}$ and Zheng L: Curcumin inhibits neuronal and vascular degeneration in retina after ischemia and reperfusion injury. PLoS One 6: e23194, 2011

54. Wang S, Ye Q, Tu J, Zhang M and Ji B: Curcumin protects against hypertension aggravated retinal ischemia/reperfusion in a rat stroke model. Clin Exp Hypertens 39: 711-717, 2017.

55. Limoli PG, Vingolo EM, Limoli C and Nebbioso M: stem cell surgery and growth factors in retinitis pigmentosa patients: Pilot study after literature review. Biomedicines 7: 7, 2019.

56. Vasireddy V, Chavali VR, Joseph VT, Kadam R, Lin JH, Jamison JA, Kompella UB, Reddy GB and Ayyagari R: Rescue of photoreceptor degeneration by curcumin in transgenic rats with P23H rhodopsin mutation. PLoS One 6: e21193, 2011.

57. Emoto Y, Yoshizawa K, Uehara N, Kinoshita Y, Yuri T, Shikata $\mathrm{N}$ and Tsubura A: Curcumin suppresses N-methyl$\mathrm{N}$-nitrosourea-induced photoreceptor apoptosis in Sprague-Dawley rats. In Vivo 27: 583-590, 2013.

58. Li Y, Sun W, Han N, Zou Y and Yin D: Curcumin inhibits proliferation, migration, invasion and promotes apoptosis of retinoblastoma cell lines through modulation of miR-99a and JAK/STAT pathway. BMC Cancer 18: 1230, 2018.

59. Bar-Sela G, Epelbaum R and Schaffer M: Curcumin as an anti-cancer agent: Review of the gap between basic and clinical applications. Curr Med Chem 17: 190-197, 2010.

60. Burlacu A, Genovesi S, Popa IV and Crisan-Dabija R: Unpuzzling COVID-19 prothrombotic state: are preexisting thrombophilic risk profiles responsible for heterogenous thrombotic events? Clin Appl Thromb Hemost 26: 1076029620952884, 2020

61. Moghadamtousi SZ, Kadir HA, Hassandarvish P, Tajik H, Abubakar S and Zandi K: A review on antibacterial, antiviral, and antifungal activity of curcumin. Biomed Res Int 2014: 186864, 2014

62. Praditya D, Kirchhoff L, Brüning J, Rachmawati H, Steinmann J and Steinmann E: Anti-infective properties of the golden spice curcumin. Front Microbiol 10: 912, 2019.

63. Taurone S, Ripandelli G, Pacella E, Bianchi E, Plateroti AM, De Vito S, Plateroti P, Grippaudo FR, Cavallotti C and Artico M: Potential regulatory molecules in the human trabecular meshwork of patients with glaucoma: Immunohistochemical profile of a number of inflammatory cytokines. Mol Med Rep 11: $1384-1390,2015$

64. Stanton CM and Wright AF: Inflammatory biomarkers for AMD. Adv Exp Med Biol 801: 251-257, 2014.

65. Abcouwer SF: Angiogenic factors and cytokinesin diabetic retinopathy. J Clin Cell Immunol Suppl 1: 1-12, 2013.

66. Chua J, Vania M, Cheung CM, Ang M, Chee SP, Yang H, Li J and Wong TT: Expression profile of inflammatory cytokines in aqueous from glaucomatous eyes. Mol Vis 18: 431-438, 2012

67. Bianchi E, Ripandelli G, Feher J, Plateroti AM, Plateroti R, Kovacs I, Plateroti P, Taurone S and Artico M: Occlusion of retinal capillaries caused by glial cell proliferation in chronic ocular inflammation. Folia Morphol (Warsz) 74: 33-41, 2015.

68. Taurone S, Ralli M, Nebbioso M, Greco A, Artico M, Attanasio G Gharbiya M, Plateroti AM, Zamai L and Micera A: The role of inflammation in diabetic retinopathy: A review. Eur Rev Med Pharmacol Sci 24: 10319-10329, 2020

69. Aggarwal BB and Harikumar KB: Potential therapeutic effects of curcumin, the anti-inflammatory agent, against neurodegenerative, cardiovascular, pulmonary, metabolic, autoimmune and neoplastic diseases. Int J Biochem Cell Biol 41: 40-59, 2009.

This work is licensed under a Creative Commons Attribution-NonCommercial-NoDerivatives 4.0 International (CC BY-NC-ND 4.0) License. 